УДК 378.4

DOI: $10.23951 / 1609-624 X-2020-1-77-85$

\title{
ПРИМЕНЕНИЕ ИНФОРМАЦИОННЫХ ТЕХНОЛОГИЙ В ПРЕПОДАВАНИИ ДИСЦИПЛИНЫ «ЦВЕТОВЕДЕНИЕ И КОЛОРИСТИКА» (НА ПРИМЕРЕ ПРОФИЛЯ «ПРИКЛАДНАЯ ИНФОРМАТИКА В ДИЗАЙНЕ»)
}

\author{
А. В. Золкина, О. М. Науменко
}

Национальный исследовательский технологический университет «МИСиС», Москва

\begin{abstract}
Введение. Представлена актуальность применения информационных технологий при преподавании дисциплины «Цветоведение и колористика» по профилю обучения «Прикладная информатика в дизайне» направления подготовки «Прикладная информатика» бакалавриата. Дан анализ истории цветоведения и истории преподавания дисциплины «Цветоведение и колористика», а также обзор подходов практико-ориентированного обучения в учебной и проектной деятельности будущих информатиков в дизайне.

Материал и методы. Были проведены традиционные лекционные, практические занятия и курсовое проектирование, а также занятия и курсовое проектирование с внедрением информационных технологий в процессе преподавания дисциплины «Цветоведение и колористика». Использовалась система LMS Canvas. Далее был проведен педагогический эксперимент в форме опроса с последующим анализом по результатам внедрения инновационных информационных методов в педагогический процесс.

Результаты и обсуждение. Приведены примеры успешного применения информационных технологий и электронных образовательных ресурсов на кафедре АПД НИТУ МИСИС в преподавании дисциплины «Цветоведение и колористика» для студентов бакалавриата по профилю «Прикладная информатика в дизайне». С помощью средств электронного образовательного ресурса LMS Canvas создана цифровая среда «Цветоведение и колористика» по профилю «Прикладная информатика в дизайне» и организовано виртуальное взаимодействие преподавателя со студентами. В дополнении к классическим методам изучения дисциплины посредством LMS Canvas реализована возможность интерактивного обучения, позволяющая присылать работы для проверки в электронном виде. Появилась возможность активного обсуждения возникающих вопросов в режиме онлайн, дистанционной проверки присланных студентом предварительно сфотографированных или отсканированных работ и отправка работ, требующих дополнения или редакции на доработку. Система LMS Canvas позволяет структурировать и систематизировать теоретический материал в доступной для студента форме, контролировать сроки «открытия» и «закрытия» каждого следующего раздела дисциплины, устанавливать необходимые преподавателю «дедлайны», фиксировать даты контрольных работ и автоматически оповещать обучающихся об их приближении. Появилась возможность создания базы данных с электронными портфолио студентов для демонстрации работодателям. Обсуждение результатов внедрения инновационных информационных методов было реализовано с помощью электронного опроса с использованием Google Forms, который выявил рост интереса к дисциплине «Цветоведение и колористика» в процессе использования электронных обучающих ресурсов и повышение скорости освоения материала.

Заключение. Применение информационных технологий в преподавании дисциплины «Цветоведение и колористика» на примере профиля «Прикладная информатика в дизайне» на кафедре АПД НИТУ «МИСиС» способствует повышению уровня приобретаемых обучающимися компетенций; зафиксирован рост интереса к дисциплине и увеличение понимания студентами направления подготовки 09.03.03 процесса дизайнерского проектирования. Введение информационных инновационных форм и методов обучения студентов позволяет усовершенствовать методические основы профессионального образования в области дизайна и способствует усилению творческой и профессионально-практической части обучения информатиков-дизайнеров.
\end{abstract}

Ключевые слова: высшее образование, качество образования, информатизаичя высшего образования, электронные образовательные ресурсы, прикладная информатика в дизайне, ияветоведение, колористика.

\section{Введение}

Дисциплина «Цветоведение и колористика» изучается в рамках направления подготовки «Прикладная информатика в дизайне» в профессиональном цикле и служит основой для научно-исследовательской работы (НИР), учебной и производственной практик обучающихся. Целями данной дисциплины являются приобретение знаний по теории цветоведения и колористики, изучение методов подбора гармоничных цветовых сочетаний, умение применять знания по цветоведению и колористике в дизайнерской деятельности. Задачи этой дисциплины - сформировать представления о хроматических и ахроматических цветах и их свойствах, колорите, цветовых гаммах и цветовых контрастах, привить навыки подбора цветовых гармоний и колорита, развить колористическое мышление и цветовосприятие. Неотъемлемыми составляющими содержания являются основные понятия цветоведения и колористики, типы и виды колорита, физиология цветовосприятия, свойства цвета, символика цвета, построение цветовых гармоний, допол- 
нительные цвета, цветовая гамма, виды цветовых контрастов, контраст и нюанс, особенности цветопередачи на различных типах носителей, пространственное воздействие теплых и холодных цветов, цветные рефлексы, дизайн печатной продукции, логотипа, презентации с использованием эмоционального и физиологического воздействия цветов. Данная дисциплина представляет собой единое целое, но логически связана с дисциплинами «Рисунок и живопись», «История изобразительного искусства и культуры». В соответствии с требованиями ФГОС ВО и образовательными стандартами Национального исследовательского технологического университета «МИСиС» (НИТУ «МИСиС») по профилю «Прикладная информатика в дизайне» направления подготовки 09.03.03 «Прикладная информатика» (уровень бакалавриата) комплексная учебно-профессиональная деятельность студентов объединяет художественнотворческую, проектную и производственно-технологическую деятельность. Практическая реализация учебно-профессиональной деятельности требует совершенствования методики и практики дизайн-технологий, в частности в области цветоведения и колористики. Педагогические подходы к процессу профессионального образования в области дизайна должны рассматриваться также и с точки зрения изучения вопросов цветовой гармонизации как профессиональной компетенции дизайнера.

В современном мире все более востребованы задачи разработки и реализации на практике новых подходов к образовательному процессу, информационных ресурсов и технологий, а также комплексной оценки художественных явлений искусства и дизайна, имеющих существенное влияние на формирование подходов в реализации педагогической и учебно-профессиональной деятельности $[1,2]$ Тенденции развития приоритетов в дизайне позволяют увидеть перспективы профессионального образования в контексте общероссийских и мировых художественных процессов. В то же время применение цифровых технологий, электронных образовательных ресурсов и интерактивных методов взаимодействия преподавателей со студентами позволяет значительно расширить диапазон приобретаемых знаний, умений, навыков и компетенций обучающихся [3].

Именно поэтому методика применения инновационных информационных технологий на кафедре Автоматизации проектирования и дизайна (АПД) НИТУ «МИСиС» в преподавании дисциплины «Цветоведение и колористика» для студентов бакалавриата по профилю «Прикладная информатика в дизайне» направления подготовки 09.03.03 «Прикладная информатика» в настоящее время особенно актуальна.
Цель исследования заключается в выявлении перспектив применения инновационных информационных технологий на кафедре АПД НИТУ «МИСиС» в преподавании дисциплины «Цветоведение и колористика». Для достижения поставленной цели необходимо было решить следующие задачи: выполнить обзор подходов практико-ориентированного обучения в учебно-профессиональной и проектной деятельности будущих информатиков в дизайне; выявить и проанализировать основные теоретические разработки и практические методы применения информационных технологий и электронных образовательных ресурсов в преподавании дисциплины «Цветоведение и колористика».

\section{Исторический обзор и анализ литературных источников}

Цветоведение развивалось и формировалось как учение в эпоху Возрождения. Сохранились трактаты, обобщающие практические разработки художников и ученых Ч. Ченнини, Леонардо да Винчи, А. Дюрера. Громадный вклад в развитие знаний о природе света и цвета внесли И. Ньютон, В. Гете и др. Отечественные и зарубежные ученыеисследователи Р. Арнхейм, К. Ауэр, Г. Фрилинг, Н. Н. Волков, В. Н. Козлов, В. М. Шугаев, В. А. Филин, Р. Л. Степучев, М. О. Сурина, Л. Н. Миронова и ряд других занимались изучением цвета с позиций психофизиологического, психологического и эстетического воздействия. Использование законов и методов цветовой гармонизации в искусстве и в дизайне обусловлено сложившимися цветовыми ассоциациями, семантикой и символикой цвета $[4,5]$. Традиционные методы преподавания цветоведения основаны на закономерностях восприятия цвета и изображения цвета [4]. Разработкой методов цветовой гармонизации с учетом восприятия цвета и пространства занимались теоретики дизайна, педагоги и художники И. Иттен, В. Кандинский, М. В. Матюшин. Сформулированные ими законы формы и цвета легли в основу преподавания школ дизайна во всем мире. И. Иттен ставит задачи развития творческих сил и художественных способностей студентов, направленных на получение своеобразия их работ, которые определяются особенностями восприятия, личными переживаниями обучающихся, сочетанием субъективного и объективного в решении проблем формы и цвета [2].

Московская школа дизайна отличается как замечательными традициями, так и уникальной творческой интерпретацией художественного материала (произведения искусства, артефакты традиционной и современной культуры). Педагогическая система дизайнерского образования в России, сочетающая принципы взаимоотношений препода- 
вателя (мастера) и студентов (учеников) - «объективный метод» - апробирована в московских вузах и экспериментальных творческих мастерских ВХУТЕМАС (ВХУТЕИН), СТрогановской высшей промышленной академии, МАРХИ и др. Ведущие преподаватели А. Родченко, А. Веснин, Н. Ладовский отрабатывали методику проектирования графической конструкции и макетов с использованием различных инструментов, материалов и приспособлений для получения новых цветофактурных, пропорциональных, ритмических решений образной формы. Экспериментальную мастерскую возглавлял М. В. Матюшин, который проводил мастерклассы по формированию творческого потенциала своих учеников. Задача научно-исследовательской работы заключалась в выявлении опытным путем закономерностей взаимодействия средств пластического языка, формы, цвета и звука в различных условиях окружающей среды. Эксперименты с оптическим смешением цветов на плоскости, предвосхитившие современные компьютерные эффекты, проводил В. Вазарели. На сегодняшний день широко используется электронная система идентификации и подбора цвета Пантон (Pantone Matching System) [6]. Важным методологическим признаком системы Пантон служит перечень специальных ключевых слов, которые можно применять для обозначения того или иного цвета на интернет-сайтах, при выполнении проектов на языках программирования для Web (HTML, CSS, JavaScript, Flash и др.).

Кафедра Автоматизации проектирования и дизайна Института информационных технологий и автоматизированных систем управления (ИТАСУ) НИТУ МИСиС была образована слиянием кафедр «Системы автоматизированного проектирования» (САПР) и «Инженерной графики и дизайна» (ИГД). Кафедра САПР занималась разработкой и проектированием информационного, программного и др. видов обеспечения автоматизированных компьютерных систем. Кафедра ИГД охватывала спектр технологических задач, связанных с визуализацией от инженерной графики до различных аспектов дизайна. Каждая кафедра, участвующая в формировании АПД НИТУ НИТУ «МИСиС», имела богатую историю и сложившиеся коллективы. Объединение их в единую кафедру повлияло на увеличение научного, педагогического и творческого потенциала и способствовало активизации применения инновационных информационных технологий на объединенной кафедре в преподавании дисциплины «Цветоведение и колористика» для студентов бакалавриата по профилю «Прикладная информатика в дизайне».

\section{Результаты и обсуждение}

Далее следует подробно рассмотреть применение инновационных информационных технологий в преподавании дисциплины «Цветоведение и колористика». На сегодняшний день уже привычной для обучающихся НИТУ «МИСиС» стала электронно-библиотечная система, позволяющая хранить и демонстрировать учебные материалы, такие как пособия, методические рекомендации, дополнительная литература и пр., в едином окне доступа. Контроль посещаемости и успеваемости студентов проводится при помощи использования электронных ресурсов - размещенных в сети электронных журналов, которые позволяют агрегировать данные о студентах, систематизировать, обобщать и анализировать данные. Внедрение электронных журналов позволило усовершенствовать систему контроля качества образовательного процесса и осуществить поэтапный переход на балльно-рейтинговую систему оценки знаний обучающихся. Автоматический подсчет накопленных обучающимися баллов и простановка аттестации значительно сократили время и трудовые ресурсы, затрачиваемые преподавателем на рутинную работу.

Применение системы смешанного обучения студентов, эффективность которой была неоднократно подтверждена исследователями феномена информатизации образования [7], было апробировано на примере дисциплины «Цветоведение и колористика». Средствами электронного образовательного ресурса LMS Canvas создана цифровая среда по данной дисциплине и организовано виртуальное взаимодействие преподавателя со студентами. В дополнение к классическим методам изучения дисциплины «Цветоведение и колористика», описанным выше, появилась возможность интерактивного синхронного и асинхронного общения. Активно используется модуль «задания», позволяющий присылать работы в электронном виде на проверку преподавателю. Появилась возможность активного обсуждения возникающих вопросов в режиме онлайн [8], дистанционной проверки присланных студентом предварительно сфотографированных или отсканированных работ и отправка работ, требующих дополнения или редакции на доработку. Система LMS Canvas позволяет структурировать и систематизировать теоретический материал в доступной для студента форме, контролировать сроки «открытия» и «закрытия» каждого следующего раздела дисциплины, устанавливать необходимые преподавателю «дедлайны», фиксировать даты контрольных работ и автоматически оповещать обучающихся об их приближении. Инструментарий тестового контроля знаний, в классическом виде недостаточно приемлемый для такой дисциплины, как «Цветоведение и колористика», в данном случае способен удовлетворить требованиям встраивания изображений непосредственно в вопрос так же, как и отображения в вариантах ответа необходимых графических элементов. 
Усовершенствование учебного процесса средствами использования цифровых технологий и электронных образовательных ресурсов, технологией сканирования, фотографирования и обработки изображений, применением обычных и трехмерных принтеров, печатью в цвете, использованием электронных папок студентов, а также систем электронных портфолио студентов направлено на изменение ролевых функций преподавателя и студента и повышение качества высшего образования. Так, например, выполнение курсовых проектов по дисциплине «Цветоведение и колористика» начинается с ручного эскизирования, а затем построения $2 \mathrm{D}-$ и $3 \mathrm{D}$-моделей с последующей визуализацией.

Для оформления курсовых проектов, помимо возможностей кафедральной изостудии с ее наглядными пособиями по колористике и цветотехнике, красками, мольбертами и другими художественными материалами, используются специализированные компьютерные залы кафедры АПД с программным обеспечением, предназначенным для визуализации, компьютерного моделирования, анимации, графики и дизайна. На кафедре функционирует «Дизайн-студия», где осуществляется дополнительное обучение всех желающих студентов не только рисунку, живописи и колористике, но и компьютерной графике и визуализации. Кафедра оснащена современными лабораториями, в которых постоянно обновляются графические программные продукты, такие как КОМПАС 3D, Solid Works, Autodesk Inventor, 3D Max, Corel Draw, Photoshop, Revit и многие другие.

Сочетание перечисленных электронных образовательных ресурсов, цифровых технологий, современных интерактивных средств обучения, программных продуктов и комплексов позволяет сформировать целостную структуру современного образовательного процесса, имеющего инновационную направленность $[9,10]$. В связи с тем что отличительной особенностью реализации программы бакалавриата направления подготовки «Прикладная информатика в дизайне» кафедрой АПД НИТУ «МИСиС» является подготовка профессионалов «два в одном», подобная инновационная направленность становится крайне важным фактором образовательного процесса. Каждый выпускник-информатик может работать в двух областях сразу - как дизайнер и как специалист по информационным технологиям, совмещая функции коллектива разработчиков в одном лице и обеспечивая мобильность на рынке труда при реализации заказов. В процессе обучения студентов по профилю «Прикладная информатика в дизайне» изучаются как технические, так и творческие дисциплины, направленные на освоение базовых приемов дизайнерского мышления, приобретение навыков по использованию инструментария для реализации дизайн-проекта: рисунок и живопись, композиция, цветоведение и колористика, шрифты и визуальные коммуникации, компьютерная графика, инструментальные средства дизайна видео-продукции, полиграфической продукции, технологии трехмерного моделирования и др. Профессиональная компетентность выпускников подобного направления, стоящего на стыке цифровых технологий и дизайна, безусловно связана с приобщением к использованию электронных ресурсов в образовательном процессе.

Сегодня применение современных цифровых технологий в системе образования и профессиональной подготовке студентов вывели научную работу студентов на новый уровень: в коммуникациях (совместное взаимодействие студентов через сеть Интернет); в возможности визуализации объектов (3D-технологии), в способах воссоздания объектов через цифровые модели (путем цифрового прототипирования); в материализации (распечатка на 3D-принтере и станках с числовым программным управлением для получения из модели реальных объектов из различных материалов). Применение современных программных средств и цифровых технологий способствует развитию творческой инициативы у студентов, закреплению умений и знаний для их успешной профессиональной деятельности. Работа над творческими проектами по дисциплине «Цветоведение и колористика» с использованием 3D-моделирования с последующим получением реального прототипа, безусловно, становится для студентов увлекательным процессом, это может способствовать их привлечению к более активному совмещению знаний и практических навыков и из области цветотехники, и из области цифровых технологий при подготовке выпускных квалификационных работ (ВКР) и проведении собственных научных исследований [11]. Примером этому могут служить успешно выполненные многочисленные работы студентов последних лет: «Разработка эскиз-проекта Студии дизайна», «Разработка многофункционального динамического сайта-портфолио дизайнера», «Разработка сайта-визитки», «Дизайн 3D-модели сувенирной медали в современной программной среде», а также творческий студенческий проект «3D-моделирование комплекта сувенирной продукции» и др. $[11,12]$.

Формирование современной обучающей среды позволило выявить и внедрить стратегию новой проектной культуры практико-ориентированного характера обучения с активным использованием информационных технологий и выявить следующие положительные тенденции при изучении дисциплины «Цветоведение и колористика»: 
1. Реализация различных творческих проектов с применением информационных технологий в обучающей среде информационно-креативного пространства способствует развитию профессиональной мотивации и вовлеченности студентов в учебно-профессиональную деятельность.

2. Методологической основой работы становится единство обучения и воспитания в учебно-профессиональной деятельности с применением компьютерных технологий.

3. Кафедра обретает роль профессионально ориентированной интегрированной творческой площадки, включающей организацию и проведение мастер-классов, дней «открытых дверей» и других форм профессиональной ориентации, активного обучения молодежи $[3,9]$.

4. Для студентов создаются условия достижения задач разработки новых объектов дизайна с активным применением инновационных информационных технологий.

На кафедре АПД НИТУ «МИСиС» были проведены комплексные практические занятия и мастерклассы, направленные на реализацию применения информационных технологий и цифровых ресурсов в работах студентов. Проводился анализ прототипов, формировалась концепция с учетом художественно-эстетических особенностей нового проектного образа. Выполнение этапов индивидуального творческого задания с применением различных приемов создания цветовой композиции подразумевало и работу в команде, и групповую рефлексию на всех этапах. При работе вручную (при подборе оттенков на палитре) и при работе на компьютере применялись таблицы цветовых гармоний и цветовой изменяемости, которые предназначены для реализации методов воспроизведения цвета. Использовались контрасты и нюансы как средства гармонизации композиции [4]. Для достижения визуального воздействия применялась ритмическая организация цветовых элементов. Использовались отечественные и зарубежные разработки: система Манселла; система Оствальда; «Атлас стандартных образцов цвета» НПО ВНИИМ и др. Систематизация цветов производилась при помощи колориметрического способа и способом цветных эталонов. Инструменты для подбора цветов и генерации цветовых схем основаны на методе аддитивного и субтрактивного смешивания (воспроизведения) цвета, в результате применения которого осуществляется гармонизация с помощью ручных, а также компьютерных таблиц смешивания цветов и синтеза оттенков, которые позволяют получить нужный оттенок для реализации проектного образа [6]. Приемы творческого анализа и синтеза цветовых сочетаний были продемонстрированы в авторских работах студентов на Международной выставке-конкурсе графики в Государственном выставочном зале «Чертаново» в Москве. Работа в группе потребовала согласования всех этапов учебно-профессиональной деятельности с учетом авторских разработок каждого студента, личностного эмоционального содержания художественно-эстетических предпочтений. Выбор и использование определенной цветовой палитры были проведены в зависимости от целевого назначения проекта по следующим основным направлениям: следование фирменному стилю, в том числе с применением элементов цветовой символики; использование традиционных и экспериментальных цветовых гармоний и фактур в процессе создания авторских объектов современного дизайна (интерьер, арт-объекты, сувениры, инсталляции); корректировка авторского решения проектного задания с учетом художественных стилей, актуальной цветовой гаммы и перспективных модных тенденций; выстраивание принципов цветовой гармонии с учетом цветотипа заказчика и цветопластических особенностей окружающей среды. Студенты и выпускники кафедры АПД участвовали в международных творческих и образовательных проектах в области дизайна.
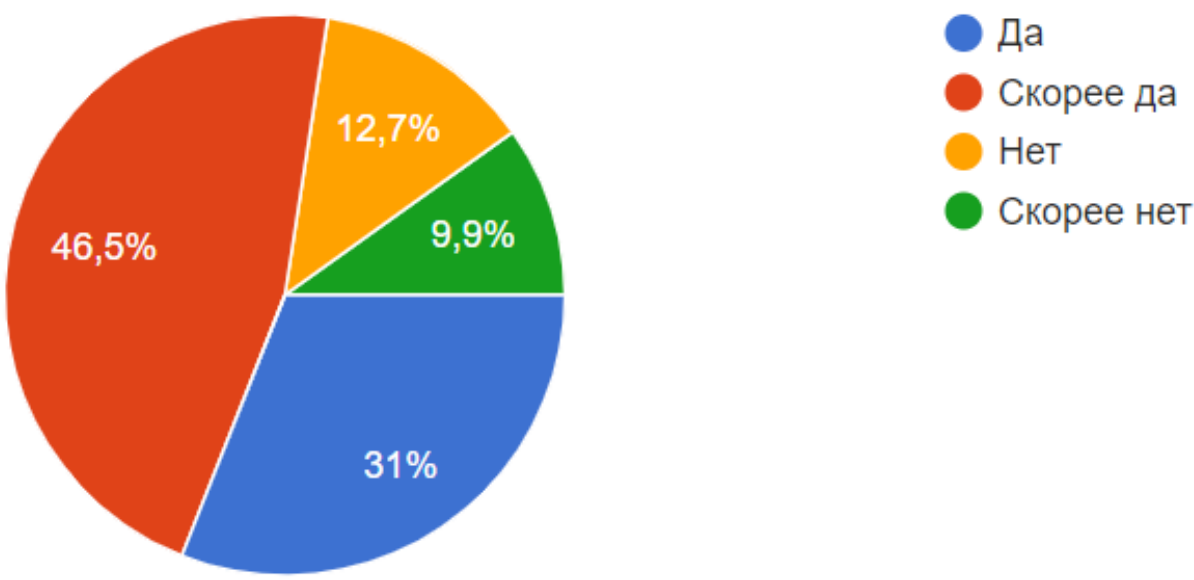

Рис. 1. Рост интереса к дисциплине в процессе использования ЭОР 

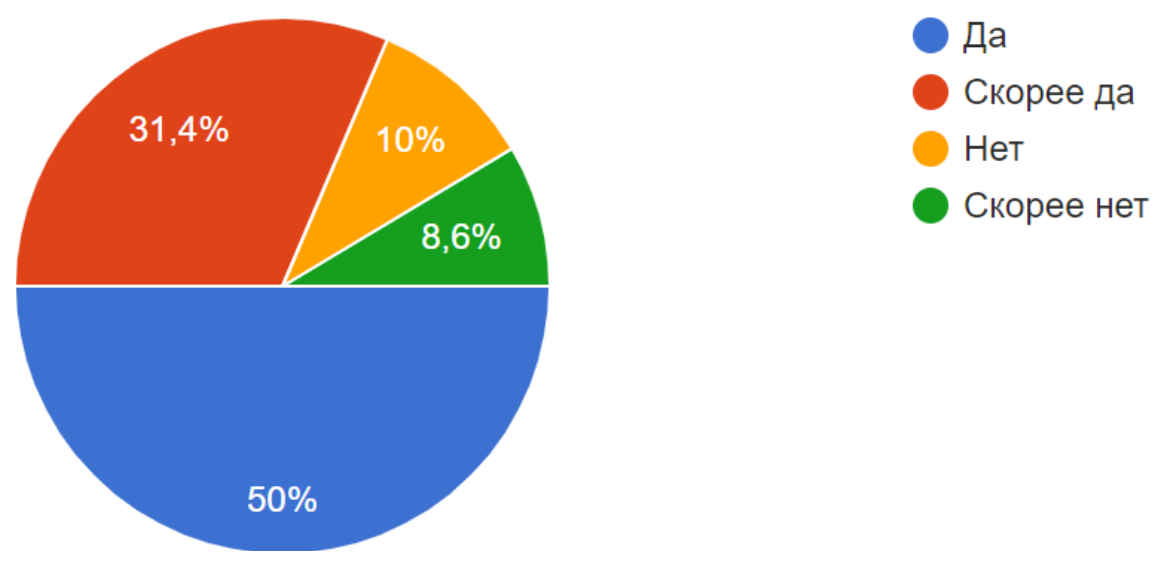

Рис. 2. Мнение обучающихся по вопросу адаптации компетенций под действующие реалии рынка труда

В целях выявления истинного уровня заинтересованности студентов в обучении при помощи электронных образовательных ресурсов был проведен педагогический эксперимент в форме опроса. Опрос был реализован авторами настоящей статьи в режиме онлайн с использованием одного из самых популярных инструментов дистанционного взаимодействия с аудиторией - Google Forms. В опросе принял участие 71 студент из пяти академических групп, обучающихся в НИТУ «МИСиС». По результатам проведенного опроса можно сделать следующие выводы: 81,7 \% респондентов считают, что работа в системе LMS Canvas помогает им при изучении дисциплины «Цветоведение и колористика»; 78,9 \% считают, что электронный образовательный ресурс принес пользу при осуществлении курсового проектирования по этой же дисциплине. При анализе ответов студентов на вопрос «Возрастает ли Ваш интерес к дисциплине "Цветоведение и колористика" в процессе использования электронных образовательных ресурсов?» был получен результат, представленный на рис. 1.

Также по результатам проведенного опроса можно сделать вывод об увеличении понимания студентами процесса творческого дизайнерского проектирования. Респонденты, считающие что их собственное понимание дисциплины не улучшилось, составляют лишь 15,7 \% от числа опрошенных. Подавляющее большинство обучающихся $(81,3 \%)$ считают, что внедрение различных видов информационных технологий в обучение по дисциплине «Цветоведение и колористика» определенно благоприятствует общему уровню социализации специалистов в эпоху цифровых технологий, так как создает информационно-креативное пространство в учебных аудиториях, изостудиях и лабораториях. На вопрос «Происходит ли более быстрая адаптация приобретенных компетенций по дисциплине «Цветоведение и колористика» под действующие реалии производства при внедрении информационных технологий?» были получены ответы, графически представленные на рис. 2.

Отвечая на вопрос о том, способствует ли развитию профессиональной мотивации процесс реализации различных творческих проектов с применением информационных технологий в обучающей среде, однозначно положительно ответили $47,9 \%$, вариант «скорее да» отметили еще $32,4 \%$ студентов. 78,5\% респондентов высказывают мнение о том, что обучение на курсе «Цветоведение и колористика» с применением цифровых технологий повышает скорость освоение учебного материала и практически абсолютное большинство опрошенных подтвердили, что их профессиональная область знаний «Прикладная информатика в дизайне» становится для них более интересной, когда в процессе обучения используются электронные образовательные ресурсы.

\section{Заключение}

Подводя итоги, можно сделать следующие выводы:

- применение информационных технологий и цифровых ресурсов на кафедре АПД НИТУ «МИСиС» в преподавании дисциплины «Цветоведение и колористика», по мнению студентов и выпускников, повысило уровень приобретаемых обучающимися компетенций и конкурентоспособность на рынке труда, так необходимые в современную «цифровую эпоху» глобальной информатизации;

- благодаря электронным образовательным ресурсам появилась возможность прослеживать ход выполнения работ и сохранять работы в виде базы данных - электронного портфолио студентов для дальнейшей архивации или демонстрации потенциальным работодателям; 
- в процессе апробации технологии применения электронных образовательных ресурсов и по результатам проведенного опроса был зафиксирован рост интереса к дисциплине и очевидное увеличение понимания студентами направления подготовки 09.03.03 «Прикладная информатика» процесса творческого дизайнерского проектирования.

\title{
Список литературы
}

1. Алексеева Н. Р., Герасимова А. Г., Лавина Т. А. Подготовка будущего специалиста в области рекламы и дизайна к профессиональной деятельности в условиях использования информационных и коммуникационных технологий // Современные проблемы науки и образования. 2017. № 3. С. 106-111.

2. Иттен И. Искусство цвета / пер с нем. и предисл. Л. Монаховой. М.: Изд. Д. Аронов, 2001. 96 с.

3. Ломоносова Н. В., Золкин Д. В. Методика создания и внедрения новой магистерской программы в условиях информатизации высшего образования // Открытое и дистанционное образование. 2017. № 2 (66). С. 52-57.

4. Алиева Н. 3. Физика цвета и психология зрительного восприятия. М.: Издат. центр «Академия», 2008. 208 с.

5. Матюшин М. А. Справочник по цвету. Закономерность изменяемости цветовых сочетаний. М.: Издатель Д. Аронов, 2007. 77 с.

6. Pantone Matching System. URL: http://tehtab.ru/Guide/GuidePhysics/LightAndColor/ColorCodification/ColorsMixing/ (дата обращения: 7.09.2018).

7. Ломоносова Н. В. Основные принципы проектирования системы смешанного обучения в вузе // Преподаватель XXI век. 2017. № 2, ч. 1 . C. $64-71$.

8. Ломоносова Н. В., Золкина А. В. Управление качеством самостоятельной работы студентов вуза в условиях системы смешанного обучения // Экономика образования и управление образованием: современные научные исследования и разработки: сб. науч. тр. по материалам I Междунар. научно-практ. конф. Калининград: НОО «Профессиональная наука», 2016. С. 236-243.

9. Осипова О. П. Процесс создания и внедрения электронных образовательных ресурсов // Народное образование. 2015. № 4. С. $127-133$.

10. Осипова О. П. Основные этапы педагогического проектирования и экспертизы электронных образовательных ресурсов // Открытое и дистанционное образование. 2015. № 2 (58). С. 76-82.

11. Левченко Р. В., Мокрецова Л. О., Науменко О. М. Опыт использования современных программных средств в курсовой научно-исследовательской работе студентов: сб. тр. VII Междунар. научно-практ. интернет-конф. «Проблемы качества графической подготовки студентов в техническом вузе: традиции и инновации» (КГП-2017). Пермь, 2017. С. 422-428.

12. Васильев А. А., Левченко Р. В., Морочко Я. Д., Науменко О. М. Зd-моделирование изделий из камня с использованием современных программных средств // Горный информационно-аналитический бюллетень (научно-техн. журн.). 2017. № 6. С. 391-396.

Золкина Анна Валентиновна, начальник отдела образовательных информационных технологий, старший преподаватель, Национальный исследовательский технологический университет «МИСиС» (пр. Ленинский, 4, Москва, Россия, 119049). E-mail: zolkina_anna@misis.ru

Науменко Ольга Михайловна, старший преподаватель, Национальный исследовательский технологический университет «МИСиС» (пр. Ленинский, 4, Москва, Россия, 119049). E-mail: naumencko.ol2015@yandex.ru

Материал поступил в редакичию 16.10.2019.

DOI: 10.23951/1609-624X-2020-1-77-85

\section{APPLICATION OF INFORMATION TECHNOLOGY IN TEACHING "COLOUR SCIENCE AND COLORISTICS" COURSE (THE CASE OF "APPLIED INFORMATICS IN DESIGN" PROFILE)}

\author{
A. V. Zolkina, O. M. Naumenko
}

National University of Science and Technology «MISIS», Moscow, Russian Federation

Introduction. In this paper, topicality of information technology application in teaching "Colour Science and Coloristics" course at "Applied Informatics in Design" profile of "Applied Informatics" bachelor degree field of education is validated. The analysis of the history of color science and the history of teaching the discipline "Color Science and Coloristics" is given. Approaches to practice-oriented teaching in educational and design activity of future information specialists in the field of design are described.

Material and methods. Lectures, practical studies and course design for "Colour Science and Coloristics" course were delivered (1) using conventional teaching procedures and (2) with application of information technology. In both implementations, Canvas LMS was used. Then pedagogical experiment was carried out in the form of questionnaire with the following analysis of innovative informational methods in educational process. 
Results and discussion. In this paper, example of successful application of information technology and educational learning resources at Department of Computer Aided Design of National University of Science and Technology "MISIS" in teaching "Colour Science and Coloristics" course for bachelor degree students of "Applied Informatics in Design" profile are given. Digital environment of "Colour Science and Coloristics" of "Applied Informatics in Design" profile was created using digital learning resource LMS Canvas and virtual interaction between teacher and students was implemented. Option of on-line training to the course (in addition to conventional training methods) was implemented using Canvas LMS. This option allows submitting of assignments in digital form for checking. There are options of online discussion of actual topics, remote checking of received student's depicted or scanned assignments and return of assignments, which require improvement or editing for correction. Canvas LMS allows to arrange and systemize theoretical material in the form comprehensible for student, control dates of opening and closing for every following course module, set deadlines required by teacher, fix dates of module tests and automatically announce the students about these dates. There is the option of creation of database with digital students' portfolios for demonstration to potential employers. Discussion of results of innovative informational methods was performed by digital questionnaire with application of Google Forms. The discussion indicates growth of interest to "Colour Science and Coloristics" course in the process of electronic learning resources application and increase of material acquisition rate.

Conclusion. Application of information technology in teaching "Colour Science and Coloristics" course of "Applied Informatics in Design" profile at Department of Computer Aided Design of NUST MISiS contributes to increase of level of skills acquired by students: growth of interest to the course is observed; students of 09.03 .03 profile better understand engineering and design. Implementation of innovative informational teaching forms and methods allows enhancing methodology of professional education in the field of design and facilitates enhancement of creative and professional practical parts of education of computational specialists in design.

Keywords: competence, e-learning resources, higher education, information and communication technology, quality of education, applied informatics, coloristics, design, chromatics.

\section{References}

1. Alekseyeva N. R. Gerasimova T. A., Lavina T. A. Podgotovka budushchego spetsialista v oblasti reklamy i dizayna k professional'noy deyatel'nosti v usloviyakh ispol'zovaniya informatsionnykh i kommunikatsionnykh tekhnologiy [The future specialist training in advertising and design field to the professional activity in the conditions of information and communication technologies use]. Sovremennye problemy nauki $i$ obrazovaniya - Modern Problems of Science and Education, 2017, no. 3, pp. 106-111 (in Russian).

2. Itten I. Iskustvo tsveta. Perevod s nemetskogo $v$ predisloviye L. Monakhovoy [Art of color. Translation from German and foreword by L. Monakhova]. Moscow, 2001. 96 p. (in Russian).

3. Lomonosova N. V., Zolkin D. V. Metodika sozdaniya i vnedreniya novoy magisterskoy programmiy v usloviyakh informatizatsii vysshego obrazovaniya [Methodology for development and implementation of new master's degree curriculum in conditions of computerization in higher education]. Otkrytoye i distantsionnoye obrazovaniye - Open and Distance Education, 2017, no. 2 (66), pp. 52-57 (in Russian).

4. Aliyeva N. Z. Fizika tsveta i psikhologiya zritel'nogo vospriyatiya [Color physics and philosophy of visual perception]. Moscow. 2008. 208 p. (in Russian).

5. Matyushin M. A. Spravochnik po tsvetu. Zakonomernost' izmenyayemosti tsvetovykh sochetaniy [Color reference. The pattern of variability of color combinations]. Moscow. 2007. 77 p. (in Russian).

6. Pantone Matching System. URL: http://tehtab.ru/Guide/GuidePhysics/LightAndColor/ColorCodification/ColorsMixing/ (accessed 17 October 2018).

7. Lomonosova N. V. Osnovnye printsipy proyekirovaniya sistemy smeshannogo obucheniya v vuze [Basic principles of designing the system of blended learning at the university]. Prepodavatel XXI vek, 2017, no. 2, part 1, pp. 64-71 (in Russian).

8. Zolkina A. V., Lomonosova N. V. Upravleniye kachestvom samostoyatel'noy raboty studentov vuza v usloviyakh sistemy smeshannogo obucheniya [Quality management of independent work of high school students in a blended learning system]. Ekonomika obrazovaniya $i$ upravleniye obrazovaniyem: sovremennye nauchnye issledovaniya i razrabotki: sbornik nauchnykh trudov po materialam I Mezhdunarodnoy nauchno-prakticheskoy konferentsii [Economics of education and education management: modern research and development: proceedings of the I Intern. scientific and practical. conf.]. Kaliningrad, NOO "Professional'naya nauka" Publ., 2016. Pp. 236-243 (in Russian).

9. Osipova O. P. Protsess sozdaniya i vnedreniya elektronnykh obrazovatel'nykh resursov [Process of creation and implementation of electronic educational resources]. Narodnoye obrazovaniye, 2015, no. 4, pp. 127-133 (in Russian).

10. Osipova O. P. Osnovnye etapy pedagogicheskogo proyektirovaniya i ekspertizy elektronnykh obrazovatel'nykh resursov [Main stages of instructional design and expert evaluation of electronic learning resources]. Otkrytoye i distantsionnoye obrazovaniye - Open and Distance Education, 2015, no. 2 (58), pp. 76-82 (in Russian).

11. Levchenko R. V., Mokretsova L. O., Naumenko O. M. Opyt ispol'zovaniya sovremennykh programmnykh sredstv v kursovoy nauchnoissledovatel'skoy rabote studentov [The experience of using modern software in the course research work of students]. Sbornik trudov VII Mezhdunarodnoy nauchno-prakticheskoy internet-konferentsii "Problemy kachestva graficheskoy podgotovki studentov $v$ tekhnicheskom vuze: traditsii $i$ innovatsii" [Proceedings of the VII International scientific and practical. internet conf "Problems of the quality of graphic preparation of students in a technical university: traditions and innovations"]. Perm, 2017. pp. 422-428 (in Russian). 
12. Vasil'ev A. A., Levchenko R. V., Morochko Ya. D., Naumenko O. M. 3d-modelirovaniye izdeliy iz kamnya s ispol'zovaniyem sovremennykh programmnykh sredstv [3d-modeling of stone products using modern software]. Gornyy informatsionno-analiticheskiy byulleten' (nauchnoanaliticheskiy zhurnal) - Mining Informational and Analytical Bulletin (scientific and technical journal), 2017, no. 6, pp. $391-396$ (in Russian).

Zolkina A. V., National University of Science and Technology «MISIS» (Leninskiy prospect, 4, Moscow, Russian Federation, 119049). E-mail: zolkina_anna@misis.ru

Naumenko O. M., National University of Science and Technology «MISIS» (Leninskiy prospect, 4, Moscow, Russian Federation, 119049). E-mail: naumencko.ol2015@yandex.ru 